\title{
Educación y ciudadanía: el compromiso cívico de los jóvenes españoles
}

\author{
Gonzalo Jover \\ Universidad Complutense \\ gonzalo@eucmax.sim.ucm.es
}

\section{Introducción}

El tema de la ciudadanía se ha constituido en uno de los ejes centrales del debate internacional actual, tanto en el campo de la Filosofía Política como en el de la Pedagogía. Kymlicka y Norman han destacado diversos factores que han colaborado a incrementar el interés por este tema, y que han venido a mostrar que la salud y estabilidad de los sistemas democráticos actuales, no depende sólo de condiciones estructurales, sino también de las actitudes de los ciudadanos: de su sentido de identidad y habilidad para articular ámbitos de identificación diversos, nacional, regional, étnico o religioso; de su capacidad para tolerar y trabajar junto a personas diferentes; de su disposición para participar en el proceso político y consecución del bien público y para asumir una responsabilidad personal ante cuestiones tales como la salud, el medio ambiente, etc. (Kymlicka y Norman, 1995 p. 284). Pero si el buen funcionamiento y estabilidad de los sistemas democráticos depende mucho de este tipo de actitudes, el papel de la educación se hace todavía más fundamental. Además, es evidente que en un mundo cada vez más global y único, pedagógicamente ya no basta con un concepto restringido de ciudadanía, sino que, como señala Kerry Kennedy al comienzo de la obra Citizenship Education and the Modern State, se hace preciso "trasladar el centro de atención de las necesidades de las naciones individuales a los intereses y necesidades más globales” (Kennedy, 1997, p. 3).

Ahora bien, esta ampliación hacia un concepto más abarcador de ciudadanía se acompaña de una mayor identificación con los ámbitos locales de pertenencia, en una especie de equilibrio no siemprefácil. En nuestro entorno, tenemos un ejemplo de este doble movimiento en el concepto de ciudadano de la Unión Europea, que introdujo el Tratado firmado en Maastricht en 1992 y que su sucesor, firmado en Amsterdam a finales de 1997, ha venido a reafirmar. Un concepto de ciudadanía que supone, por una parte, la integración en una unidad política más amplia, la libertad de circular, residir, trabajar o estudiar en cualquier otro país de la 
Unión, de elevar peticiones al Parlamento Europeo o de dirigirse al Defensor del Pueblo de la Unión, pero que, por otro lado, significa también una revalorización de lo cercano y lo local como ámbito más próximo de convivencia ciudadana: el derecho a votar y a ser elegido en las elecciones municipales del lugar en el que se resida, aunque no se tenga la nacionalidad de ese Estado miembro.

En el contexto de esta redefinición del espacio de la ciudadanía, la investigación que presento pretende conocer un poco mejor los resortes de lo que podríamos llamar la autopercepción y el compromiso cívico de los jóvenes españoles que han nacido, se han educado o han desarrollado la mayor parte de su existencia en el marco del ordenamiento democrático que abrió la Constitución de 1978. Los sujetos de la investigación han sido 2.200 jóvenes con edades comprendidas entre los 18 - el momento de la mayoría de edad que introdujo la propia Constitución- y los 30 años. Y, así, nos hemos preguntado: ¿qué balance hacen estos jóvenes de los veinte años de democracia? ¿qué posturas adoptan ante los valores y derechos constitucionales? ¿qué ámbito normativo consideran prioritario? ¿qué tipo de compromiso político y social mantienen? ¿cómo viven el ser ciudadanos europeos?

\section{Ficha técnica}

Ambito de la investigación: Territorio peninsular español. Principales núcleos urbanos.

Población: Jóvenes de 18 a 30 años.

Tipo de muestreo: Por cuotas.

Tamaño de la muestra: 2.200 sujetos.

Localidades de aplicación del cuestionario: Alicante, Barcelona, Bilbao, Cádiz, Castellón, Córdoba, Granada, La Coruña, León, Madrid, Málaga, Murcia, Oviedo, Pamplona, Salamanca, San Sebastián, Santander, Santiago de Compostela, Sevilla, Tarragona, Valencia, Valladolid, Vigo y Zaragoza.

\section{Estructura de la muestra}

\begin{tabular}{|c|c|c|c|c|}
\hline \multirow[b]{2}{*}{ EDAD: } & \multicolumn{2}{|c|}{ HOMBRES } & \multicolumn{2}{|c|}{ MUJERES } \\
\hline & \begin{tabular}{|l|}
$18-24$ \\
18
\end{tabular} & $25-30$ & |18-24 & $25-30$ \\
\hline $\begin{array}{l}\text { Trabajan como actividad } \\
\text { principal: }\end{array}$ & $7 \%$ & $11,6 \%$ & $10 \%$ & $\mid 16,5 \%$ \\
\hline $\begin{array}{l}\text { Estudian como actividad } \\
\text { principal: }\end{array}$ & $9,6 \%$ & $1,3 \%$ & $8,9 \%$ & $1,3 \%$ \\
\hline \begin{tabular}{|l} 
Se encuentran en paro o en \\
busca de primer empleo
\end{tabular} & $5,4 \%$ & $5,6 \%$ & $4,3 \%$ & $4 \%$ \\
\hline $\begin{array}{l}\text { Se ocupan de trabajos del } \\
\text { hogar como actividad } \\
\text { principal }\end{array}$ & $1,9 \%$ & $4,3 \%$ & $0 \%$ & $0,2 \%$ \\
\hline Otros & $2 \%$ & \begin{tabular}{|l|}
$0,6 \%$ \\
\end{tabular} & $4,2 \%$ & $1,3 \%$ \\
\hline TOTAL & $25,9 \%$ & $23,4 \%$ & $27,4 \%$ & $23,3 \%$ \\
\hline
\end{tabular}




\section{Perfil de la muestra por nivel de estudios [1]:}

\begin{tabular}{|l|c|}
\hline $\begin{array}{l}\text { Sin estudios o estudios } \\
\text { primarios: }\end{array}$ & $6,4 \%$ \\
\hline Estudios de grado medio: & $56,0 \%$ \\
\hline \hline Estudios superiores: & $37,6 \%$ \\
\hline
\end{tabular}

\section{Resultados}

\subsection{La valoración de la experiencia democrática}

Los resultados de la investigación indican que los jóvenes españoles actuales valoran positivamente la democracia como forma de gobierno, aunque no la consideran como algo perfecto. Para la mayor parte (45\%), la democracia constituye el sistema de gobierno menos malo, y para el $31 \%$ el único verdaderamente legítimo. Sin embargo, hay también un importante porcentaje para el cual la democracia es sólo una opción más entre otras igualmente válidas (11\%), cuando no una estrategia de legitimar el poder de unos cuantos (10\%) o incluso, para una pequeña minoría, una forma de llevar a la degradación social (2\%)

La opinión es igualmente positiva cuando de la democracia en general descendemos a la experiencia democrática concreta. Para la mayor parte de estos jóvenes, el balance de los veinte años de convivencia democrática transcurridos desde la aprobación de la Constitución de 1978 es bueno (54\%) o muy bueno (15\%), mientras que sólo una minoría lo considera malo (3\%) o muy malo (3\%). Con todo, la cuarta parte manifiesta algunas reservas, situándose en una posición intermedia.

\subsection{Los valores constitucionales}

La Constitución comienza su articulado estableciendo: "España se constituye en un Estado social y democrático de Derecho, que propugna como valores superiores de su ordenamiento jurídico la libertad, la justicia, la igualdad y el pluralismo político" (Art. 1.1.). El texto constitucional sienta con ello los valores o criterios superiores del marco de convivencia ciudadana. Desde una posición que trata de situarse a una distancia equidistante del iusnaturalismo y del positivismo jurídico radical, Peces Barba -uno de los “padres” de la Constitución, a quien se debe la redacción original de este artículo- ha señalado cómo tales valores tienen su fundamento último en la propia idea de la dignidad humana, pero no por ello hay que interpretarlos como criterios ahistóricos y desencarnados, sino que reflejan la coyuntura del país de aquel momento. El acuerdo que se plasma en la Constitución y en los valores superiores del artículo 1.1. como base del sistema, indica, no tiene nada de abstracto ni de lejano. "Es el acuerdo que aquí y ahora, y teniendo en cuenta todas las connotaciones de la historia reciente, hacen los españoles de 1978. No cabe duda de que esas vicisitudes de la historia de España fracaso de otras fórmulas de convivencia, confrontación violenta en la guerra civil, dictadura durante casi cuarenta años- han sido relevantes en la formación de ese consenso de los valores superiores” (Peces Barba, 1986, p. 108).

Por ello, precisamente, tiene mucho interés preguntarse cómo se sitúan 
ante esos valores los jóvenes que proceden ya de otra experiencia histórica, jóvenes que han vivido la mayor parte de su vida en el sistema constitucional. Como era de imaginar, la libertad destaca como el valor más apreciado por la juventud, siendo elegido como el más importante, al que nunca se podría renunciar, por más de la mitad de los jóvenes (51\%). En último lugar se sitúa el pluralismo (6\%). A pesar de que en la formulación de la pregunta se cambió la expresión "pluralismo político" del artículo 1.1. de la Constitución por "pluralismo" en general, éste ya no parece vivirse como una aspiración tan fuerte como podía serlo hace veinte años, cuando todavía estaba demasiado reciente la experiencia de la época anterior.

Quizás lo más llamativo sea la situación que se produce en la mitad de la escala con respecto a los criterios de la justicia (23\%) y la igualdad (20\%), sobre todo si tenemos en cuenta que, según señala el propio Peces Barba, esos cuatro valores no tienen todos la misma entidad. Los valores fundamentales, los que inspiran todo proyecto y toda diferencia política, son los de la igualdad y la libertad[2], razón por la cual la Constitución les da un tratamiento diferenciado en el artículo 9.2. La inclusión, junto a ellos, del pluralismo (político) en el artículo 1.1. responde de manera muy específica a la situación de la sociedad española de 1978, pues de hecho tal pluralismo puede entenderse como una manifestación y exigencia de la propia libertad, por lo que podría integrarse dentro de ésta. Por último, el lugar de la justicia entre estos valores "es ambiguo, puede carecer de contenido específico, sino es precisamente la realización de los valores de la libertad e igualdad” (ibid., p. 118). De acuerdo con este esquema teórico ¿qué factores pueden estar operando en las posiciones que adopta la juventud ante los valores de la igualdad y la justicia? Por un lado, parece actuar lo que se ha denominado la situación de horas bajas del ideal de la igualdad (Valcárcel, 1993), aspecto sobre el cual ya otros estudios acerca de los valores de la juventud han llamado la atención (Martín Serrano, 1994, pp. 71 y 72). La justicia, por su lado, es el concepto más inclusivo, lo que puede inclinar las elecciones. Pero la interpretación más plausible probablemente deba tener también en cuenta el carácter contextualizado de estos valores en una realidad social. Para bien o para la mal, "la justicia” ha ocupado durante los últimos años uno de los lugares centrales en el debate social de nuestro país, por lo que no es extraño que hoy aparezca ante la juventud como un ideal tan importante como hace veinte años podía serlo la aspiración al pluralismo.

\subsection{Los derechos constitucionales}

Los valores superiores del artículo 1.1. de la Constitución toman cuerpo en el conjunto de derechos que la misma recoge en su Título Primero. El gráfico siguiente plasma lo que podríamos llamar el índice de inalienabilidad de algunos de estos derechos (elegidos con la ayuda de un grupo de jóvenes de esta edad), esto es, sobre 10, la diferencia entre quienes piensan que se deberían respetar siempre y quienes estiman que según las circunstancias. 


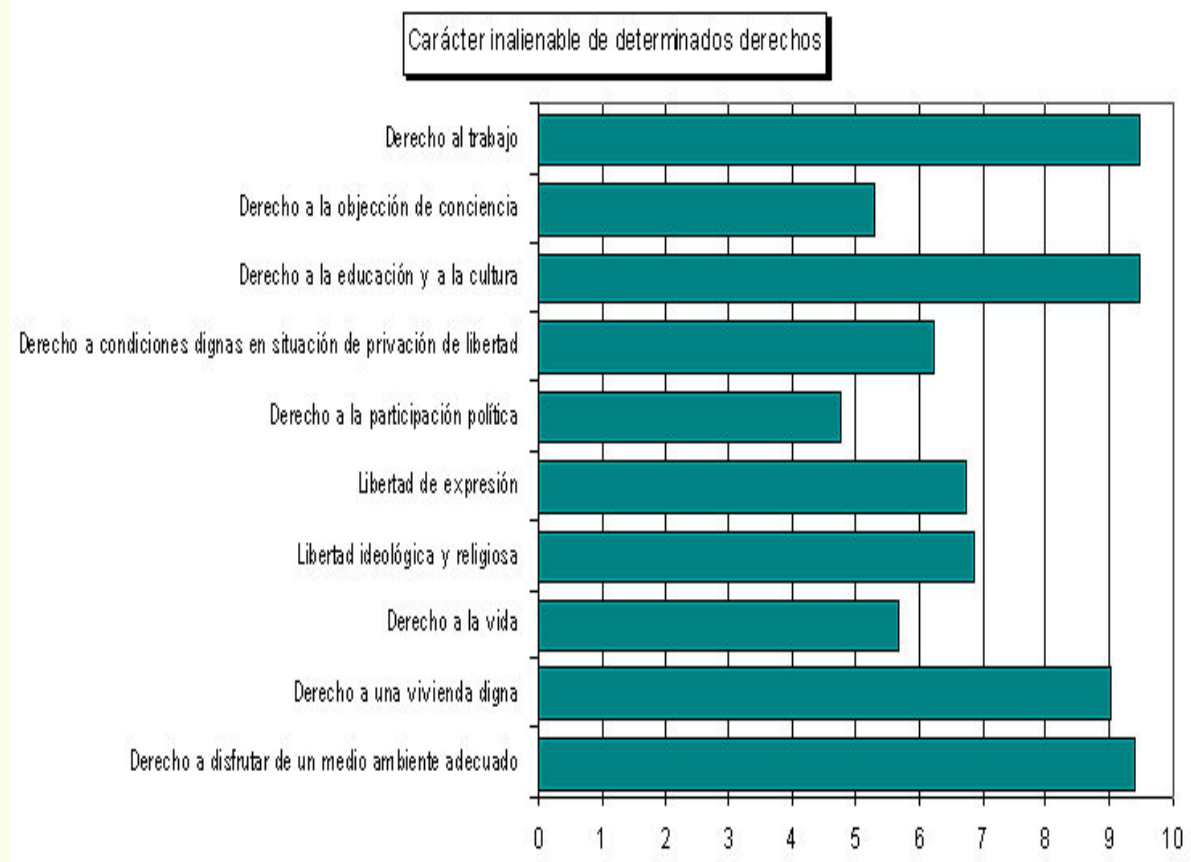

Como puede comprobarse en el gráfico, en todos los derechos quienes consideran que se deben respetar siempre sobrepasan ampliamente a quienes piensan que depende de las circunstancias (los índices son siempre sobradamente positivos). Los índices más altos los presentan los llamados derechos de segunda generación (derechos sociales, al trabajo, a la educación y la cultura, a la vivienda,...) y tercera generación (derecho a disfrutar de un medio ambiente adecuado), aquéllos, por cierto, cuya satisfacción más suele depender de condiciones, por ejemplo, económicas, y que probablemente por ello la Constitución no incluye -con la excepción del derecho a la educación- en el capítulo de "Derechos y libertades", sino en el de "Principios rectores de la política social”. Frente a éstos, las puntuaciones más bajas las reciben los derechos de primera generación o derechos civiles y políticos.

En el sistema de derechos, éstos se limitan y matizan entre sí. Además, los derechos no son realidades estáticas, sino aspiraciones en evolución (Bárcena, Gil y Jover, 1999, pp. 43-70). Pero ciertas condiciones esenciales deberían quedar siempre intactas. Por ejemplo, en estos días de toma de conciencia de la acción degradante del hombre sobre la naturaleza, nadie duda ya de la importancia de preservar ésta para las generaciones futuras, y del derecho a disfrutar de un medio ambiente adecuado. Sin embargo, posponer con respecto a éste el mismo derecho a vivir no parece muy congruente. En nuestros resultados podrían, de este modo, encontrar apoyo quienes piensan que la inclusión de cualquier aspiración ética y social en la categoría, más exigente, de los derechos humanos puede tener efectos no deseados. Con la ampliación de la categoría -hoy ya se habla de una cuarta y una quinta generación de derechos- se corre el riesgo de que lo esencial se pierda.

Al analizar el índice de inalienabilidad de los derechos en función del valor constitucional al que se da primacía, comprobamos que las posturas más circunstanciales acerca del respeto a los derechos humanos las mantienen quienes destacan el valor de la justicia (curiosa concepción), mientras que las posturas más firmes suelen corresponder a quienes se decantan por la libertad, principalmente en lo que se refiere a las libertades y derechos civiles y políticos. Pero incluso para estos jóvenes, los derechos y libertades civiles, que son, precisamente, los que encarnan el ideal o valor superior de la libertad, se sitúan en el índice de 
inalienabilidad por debajo de los sociales y ecológicos. Lo que parece producirse es, pues, una especie de contradicción entre el ideal éticopolítico y su concreción en unas exigencias determinadas. Los jóvenes valoran aquellas cuestiones y preocupaciones concretas que afectan a su vida cotidiana (el trabajo, la educación y la cultura, la vivienda...), por encima de los ideales ético-políticos, como el presupuesto democrático de la participación, que queda en el último de la escala, por debajo incluso del punto medio del cinco.

En cualquier caso, tampoco puede despreciarse la influencia que, de nuevo, ha podido tener en algunas de estas respuestas el clima que han ido generando ciertos acontecimientos sociales vividos muy intensamente en estos últimos años de experiencia democrática, lo que vendría a apoyar la tesis de Richard Rorty de que en materia de posicionamiento ante los derechos humanos la fuerza de los impulsos y sentimientos sobrepasa a menudo a la fuerza de la razón (Rorty, 1998).

\subsection{La prioridad de los ámbitos normativos}

La ciudadanía implica tanto la posesión de un conjunto de derechos, como el sentido de pertenencia a un ámbito valorativo de convivencia (IbáñezMartín, 1997). Sin embargo, esta idea ha ampliado los límites tradicionales que la circunscribían a una determinada sociedad política. Hoy se habla de una ciudadanía multicultural, global o compleja (Kymlicka, 1996; Cortina, 1997; Nussbasum, 1999; Rubio Carracedo, 2000; etc.) cuyo contexto valorativo más amplio lo representan los derechos humanos recogidos en las declaraciones y convenciones internacionales.

Números

Anteriores

El propio texto constitucional (art. 10.2) remite a la Declaración Universal de 1948 y a los demás pactos o convenios sobre derechos humanos ratificados por nuestro país, como marco de interpretación de los derechos y libertades constitucionales. Ahora bien, el problema surge por los posibles conflictos que pueden aparecer entre los diferentes contextos normativos o ámbitos de pertenencia de los que se forma parte. En tales casos ¿qué ámbito debe prevalecer? ¿por cuál apuestan los jóvenes?

Las respuestas dadas a esta pregunta por los jóvenes de nuestra investigación reflejan bien la tensión entre lo universal y lo local que caracteriza esta última etapa de la época moderna, pues si el primer lugar lo ocupan los valores universales, tal como se recogen en la Declaración Universal de 1948 (53\%), en segundo término lo hacen los valores de los ámbitos de pertenencia más cercanos (familia, amigos, grupos, etc.) (30\%) y sólo más de lejos los valores de la sociedad político-cultural a la que se pertenezca (país, nación, comunidad política, etc.) (11\%), o los valores de la religión que se posea (5\%) [3].

\subsection{El compromiso político}

La ciudadanía se activa a través del compromiso cívico. Tal compromiso cívico puede desglosarse en compromiso político y compromiso social, esto es, en el grado de implicación en un proyecto común de convivencia y en el grado de participación solidaria en un ámbito que hoy, con la ampliación de los límites de lo cívico, ya sólo puede ser el de la propia humanidad.

Respecto a la primera de estas dos dimensiones de la vida cívica, se pidió a los jóvenes que se situasen a sí mismos en una escala de compromiso 
político entre 1 , como mínimo, y 7 , como máximo. Como resultado, se obtiene una media para el conjunto de los jóvenes de 3,6, por debajo, por tanto, del punto medio del 4 [4]. La puntuación es algo menor en el tramo de edad inferior que en el superior (3,4 para el tramo de 18-24 años y 3,7 para el de 25-30), lo que puede indicar cierta tendencia a la baja en la autopercepción de compromiso político. Esta tendencia no haría sino continuar una línea ya trazada, toda vez que se ha puesto de manifiesto cómo el interés de los jóvenes por la política en los años que rodearon la aprobación de la Constitución inició un considerable descenso a partir de los ochenta (Martín Serrano, 1994, pp. 71 y 72).

Los propios jóvenes parecen, de hecho, tener esta sensación cuando se les pide que comparen en diversos aspectos su generación con la anterior. En una escala del 0 al 5, positiva y negativa, los jóvenes de hoy se consideran bastante más tolerantes $(+2,7)$ y en general felices $(+2,2)$ que los de hace quince o veinte años; algo más emprendedores $(+1,7)$ y solidarios $(+1,5)$ e incluso un poco más independientes $(+0,8)$. Pero, también se ven a sí mismos bastante menos comprometidos políticamente, siendo éste el único aspecto que presenta una relación negativa con respecto a la generación precedente $(-1,7)$.

\subsection{El compromiso social}

En lo que respecta al compromiso social de los jóvenes, un buen indicador para valorarlo es su participación en asociaciones u organizaciones de carácter social y humanitario. Pues bien, el 18\% de los jóvenes encuestados forma o ha formado parte alguna vez de este tipo de asociaciones (ONGs, organizaciones socioculturales, de ayuda a discapacitados, ecológicas, asistenciales, sanitarias, de colaboración con los países en vías de desarrollo, etc.) sin que se produzcan diferencias significativas entre hombres y mujeres, confirmando cierta tendencia a la igualdad que viene detectándose desde comienzos de la última década (Angulo Uribarri, 1995, pp. 66-67). De este 18\%, un 11\% formó parte de estas asociaciones antes pero no ahora, y un $7 \%$ lo hace actualmente.

Los resultados muestran cómo el cambio de situación familiar u ocupacional que acontece a estas edades (por ejemplo, el paso del estudio al trabajo) afecta al abandono de la participación a lo largo del periodo de edad considerado. Puede hablarse, además, de un compromiso más estable y un compromiso más esporádico, según el tiempo que se permanezca colaborando en asociaciones solidarias. Un tiempo que, para la mayor parte, se sitúa entre uno y tres años. Así mismo, esta colaboración admite formas muy variadas, desde la aportación económica hasta la participación activa con una dedicación que en no pocas ocasiones supera las 100 horas al mes. Lo más frecuente (en el 57\% de los casos), es una colaboración que se sitúa entre 5 y 50 horas mensuales, esto es, aproximadamente, de una a diez horas a la semana.

Nuestros datos no permiten extraer conclusiones en sentido longitudinal acerca de la evolución previsible de las cotas de compromiso social de la juventud española, y si bien en el transcurso de los noventa la participación en iniciativas solidarias conoció claros momentos de alza, se han detectado también indicios de estancamiento (ibid., p. 75; Martín Serrano y Velarde Hermida, 1997, pp. 168-169; Andrés Orizo, 1999, p. 74). El análisis de los movimientos asociativos juveniles durante los últimos veinte años lleva, finalmente, a Prieto Lacaci a concluir que la idea de "compromiso" no es ya la que mejor describe la actitud asociativa 
de los jóvenes. Ello no significa, comenta este autor, "que el 'militante comprometido' haya desaparecido por completo del mundo asociativo. Sin este tipo de agente, cargado de convicciones éticas y de una buena dosis de voluntarismo, no se explicaría la existencia de muchas asociaciones altruistas, políticas, religiosas o culturales. Pero la tendencia dominante no es ésta” (Prieto Lacaci, 1998, p. 99).

\subsection{La ciudadanía de la Unión Europea}

El Tratado de la Unión Europea, tanto en la versión firmada en Maastricht en 1992, como en la revisión aprobada en Amsterdam en 1997, ha sancionado el concepto de ciudadano de la Unión, concretado en un conjunto de libertades y derechos. Unos meses antes de la aprobación de la revisión del Tratado de Unión, la Comisión Europea publicó los resultados de un estudio acerca de la sensación de ciudadanía europea de los jóvenes (entre 15 y 24 años) de los Estados miembros. Como en otras ocasiones, se constata que son precisamente los jóvenes quienes suelen sentirse más europeos, en comparación con los ciudadanos de más edad. Para los jóvenes, Europa significa: libertad de movimientos (35\%), un futuro más esperanzado (34\%), mejora de la situación económica (34\%), más posibilidades de creación empleo (29\%), perspectivas de un gobierno europeo (24\%), garantía de paz (24\%)... Pero, según revela el mismo informe, los jóvenes de nuestro país suelen encontrarse entre los más escépticos con respecto a estas ventajas (Commission Européenne, 1997b, pp. 101 ss.)

Según los datos de nuestra investigación, en una escala del 1 al 7, el sentimiento de ciudadanía europea de los jóvenes españoles se sitúa en el 4,5, por encima, por tanto, del punto medio. Del informe de la Comisión Europea citado, se desprende que los jóvenes españoles identifican sobre todo la ciudadanía europea con los derechos a trabajar (61\%), instalarse permanente (50\%) o estudiar en otro país (41\%), y sólo muy secundariamente con los derechos a votar en las elecciones locales y europeas en el país de la Unión en el que residan, con independencia de la nacionalidad (14\% en cada caso) (ibid., p. 111). De nuevo, los aspectos más concretos que afectan a sus posibilidades y experiencias adquieren preeminencia sobre el presupuesto democrático de la participación.

Por último, hemos tenido oportunidad de comprobar la existencia de relación entre valoración del proceso de integración y movilidad europea. La experiencia europea, el conocimiento de otros países, repercute favorablemente en esa valoración, de modo que quienes han viajado a algún otro lugar de Europa, en su mayor parte, países de la U.E., mantienen posturas más positivas hacia el proceso de Unión que quienes no lo han hecho, especialmente cuando estos viajes se asocian a la realización de estudios y, en menor grado, cuando se han realizado por motivos laborales [5]. Estos datos vienen a apoyar empíricamente la hipótesis de la incidencia de los programas de movilidad para jóvenes y estudiantes en la construcción de la ciudadanía de la Unión (Bárcena, Gil y Jover, 1999, pp. 121-155). 
Los resultados de nuestra investigación convergen en la idea de que los jóvenes españoles realizan un balance positivo de los veinte años de convivencia democrática, pero tienen muchas dificultades para identificarse como ciudadanos activos dentro de la misma.

Si bien no se trata de un fenómeno esporádico y ahistórico, hoy concurren condiciones especiales. Por un lado, está lo que se ha llamado la desideologización del discurso y la vida política. Sabemos que existe relación entre el bajo interés que muestran muchos jóvenes por la política y las dificultades para ubicarse en el espectro político, esto es, cuanto más débil o ambigua es la autoidentificación político-ideológica menor es también el interés (Instituto de la Juventud, 1991, p. 12). El último informe del Instituto de la Juventud, sobre la juventud española de los noventa, ha puesto de manifiesto, en este sentido, algunas tendencias respecto al posicionamiento político de los jóvenes a lo largo de las dos últimas décadas, llamando especialmente la atención sobre la aparición de un contingente numeroso de jóvenes "políticamente desubicados", porque ni pueden identificarse 'a la derecha', ni tampoco posicionarse (o seguir posicionados) ‘a la izquierda’” (Martín Serrano y Velarde Hermida, 1997, p. 263). En las opciones políticas de la juventud, indica otro reciente estudio, los intereses pragmáticos terminan imponiéndose a las posiciones ideológicas (Andrés Orizo, 1999, pp. 105-106) [6]. Por otro lado, el compromiso político en el que se fundamentan los sistemas democráticos se asocia a la vida activa, al sentimiento de autonomía y participación en la construcción de la sociedad. Según nuestros resultados, quienes estudian y trabajan mantienen una opinión ligeramente más positiva de estos veinte años de gobierno democrático que quienes buscan empleo o, en el lugar más bajo de la escala, quienes realizan como actividad principal trabajos del hogar [7]. Las condiciones que retrasan la incorporación activa de los jóvenes, deben, por tanto, afectar al bajo concepto que tienen de sí mismos como artífices políticos.

Desde el punto de vista de este déficit de autoidentificación política y cívica, se explica mejor la fractura que parece existir entre los grandes ideales democráticos por los que apuesta la juventud y su concreción en unas exigencias específicas. Los mismos jóvenes para los que la libertad es el valor constitucional más irrenunciable, que se ven a sí mismos como una generación más tolerante que la de sus antecesores, o que piensan que en caso de conflicto de valores deben prevalecer los ideales universalistas, tal como se recogen en la Declaración Universal de Derechos Humanos de 1948, consideran que derechos como la libertad ideológica o religiosa, libertad de expresión, derecho a la objeción de conciencia o la misma participación política, son menos básicos e inalienables que el derecho al trabajo, a la vivienda, a la educación y la cultura o disfrutar de un medio ambiente adecuado, derechos, que, siendo importantes conquistas sociales e históricas, no parece lógico posponer, como es el caso, con respecto a los criterios éticos y políticos más elementales.

Estas actitudes de la juventud española sitúan a nuestra joven democracia en la línea de lo que viene siendo una tendencia en la vieja Europa del ideal del bienestar. Según el Eurobarómetro de la Comisión Europea, para los europeos, derechos como la educación o la vivienda se colocan en lo que hemos llamado índice de inalienabilidad, por encima de las libertades de conciencia, expresión o asociación, derecho a la participación política y derecho de asilo en caso de persecución política o religiosa, que queda en el lugar más bajo de la lista (Commission Européenne, 1997a, p. 66). Parece como si algunas cosas fuesen ya tan 
evidentes que no hubiese que preocuparse por ellas. Pero éste es precisamente el peligro que acecha a los sistemas democráticos. El riesgo de las democracias actuales, señala Charles Taylor, es que los ciudadanos terminen "convirtiéndose en ese tipo de individuos que están 'encerrados en sus corazones'; pocos querrán participar activamente en su autogobierno. Preferirán quedarse en casa y gozar de las satisfacciones de la vida privada, mientras el gobierno proporciona los medios para el logro de estas satisfacciones y los distribuye de modo general” (Taylor, 1994, p.44). La única defensa contra este riesgo, añade Taylor, consiste en la promoción de una vigorosa cultura política que fomente la participación tanto en los diversos niveles de gobierno como en las asociaciones voluntarias.

Un reciente estudio acerca de las actitudes hacia la democracia en España a lo largo de los años ochenta y noventa, a través de un análisis funcional y de cohortes, permite concluir que la democracia española se caracteriza por altos grados de legitimidad, que han permanecido estables e inmunes a las fluctuantes percepciones sobre el funcionamiento de las instituciones democráticas, en ocasiones muy negativas, acompañados de niveles igualmente altos y estables de desafección política (Montero, Gunther y Torcal, 1998). Nuestros resultados confirman esta conclusión. No se cuestiona el valor de la democracia, la cual, sin embargo, se considera algo lejano y ajeno, en lo que no se toma parte activa. Cabe preguntarse con Luz Morán y Jorge Benedicto, en su investigación sobre La cultura política de los españoles, hasta que punto estos resultados, más que una incongruencia de actitudes y comportamientos, son simplemente efecto de la "adecuación a una realidad institucional que minimiza el papel del ciudadano activo que aparecía como requisito sine qua non de las concepciones clásicas de la democracia” (Morán y Benedicto, 1995, p. 102). Pero cabe igualmente preguntarse, con estos mismos autores, en qué medida la apatía política de la población más joven no revela también cierto fracaso de los sistemas de educación (ibid., pp. 59 y 60).

La lección pedagógica de estos resultados es clara. La escuela debe asumir su responsabilidad cívica. Pero, además, pedagógicamente ya no basta con promover la adhesión al sistema y valores democráticos. Se precisa, sobre todo, impulsar una ciudadanía activa que se sienta parte en la permanente construcción de la sociedad democrática. Si algo nos ha enseñado el siglo XX es que la libertad no admite precios ni acomodos. Exige ser redescubierta cada día. Frente a quienes piensan que los sistemas democráticos se mantienen por sí mismos, o que ya habrá quien se encargue de su funcionamiento, "no debemos olvidar que la libertad y la democracia significan la participación y, por tanto, la responsabilidad de todos” (Havel, 1995, p. 30). Estas palabras las pronunció Václav Havel en el discurso que dirigió a sus conciudadanos el día de Año Nuevo de 1990, a las pocas semanas de la revolución de terciopelo. En el umbral de un nuevo siglo, es bueno que volvamos a recordarlas. Ellas encierran un programa no sólo político, sino también pedagógico.

\section{Bibliografía}

ANDRÉS ORIZO, F. (1999): Jóvenes: sociedad e instituciones. En

ELZO, J. et al. Jóvenes españoles 99. S.M., Madrid.

ANGULO URIBARRI, J. (1995): La solidaridad de la juventud. Instituto de la Juventud, Madrid.

BÁRCENA, F.; GIL, F. y JOVER, G. (1999): La escuela de la ciudadanía. Educación, ética y política. Desclée de Brouwer, Bilbao. 
COMMISSION EUROPEENNE (1997a): Eurobarometre 47. Office des Publications Officielles des Communautés Européenes, Luxembourg. COMMISSION EUROPEENNE (1997b): Les jeunes européens.

Eurobarometre 47.2 (documento informático)

CORTINA, A. (1997): Ciudadanos del mundo. Hacia una teoría de la ciudadanía. Alianza. Madrid.

ELZO, J. y GONZÁLEZ-ANLEO, J. (1999): Los jóvenes y la religión. En ELZO, J. et al. Jóvenes españoles 99. S.M., Madrid, pp. 263-354. HAVEL, V. (1995): Discursos políticos. Espasa-Calpe, Madrid. IBÁÑEZ-MARTÍN, J.A. (1997): La ciudadanía en el siglo XXI: una propuesta entre el realismo y la utopía. Seminario Internacional Complutense "Educación y ciudadanía: ideas para un currículo de educación cívica ante el tercer milenio". Madrid, octubre de 1997. INSTITUTO DE LA JUVENTUD (1991): Actitudes políticas de la juventud en España. Instituto de la Juventud, Madrid.

KENNEDY, K. (1997): Citizenship Education in Review: Past Perspectives and Future Needs. En KENNEDY, K. (Ed.): Citizenship Education and the Modern State. The Falmer Press. London, pp. 1-5. KYMLICKA, W. (1996): Ciudadanía multicultural. Paidós, Barcelona. KYMLICKA, W. y NORMAN, W. (1995): Return of the Citizen: A Survey of Recent Work on Citizenship Theory. En BEINER, R. (Ed.): Theorizing Citizenship. SUNY Press, New York, pp. 283-322. MARTÍN SERRANO, M. (1994): Historia de los cambios de mentalidades de los jóvenes entre 1960-1990. Instituto de la Juventud, Madrid.

MARTÍN SERRANO, M. y VELARDE HERMIDA, O. (1997): Informe Juventud en España 96. Instituto de la Juventud, Madrid.

MONTERO, J.R.; GUNTHER, R. y TORCAL, M. (1998): Actitudes hacia la democracia en España: legitimidad, descontento y desafección, Reis, 83, pp. 9-49.

MORAL, F. y MATEOS, A. (1999): La identidad nacional de los Jóvenes y el Estado de las Autonomías. CIS, Madrid.

MORÁN, L.M. y BENEDICTO, J. (1995): La cultura política de los españoles. Un ensayo de interpretación. CIS, Madrid.

NUSSBASUM, M.C. (1999): Patriotismo y cosmopolitismo. En

NUSSBASUM, M.C. et al. Los límites del patriotismo. Paidós, Barcelona, pp. 13-29.

PECES BARBA, G. (1986): Los valores superiores. Tecnos, Madrid. PRIETO LACACI, R. (1998): Tendencias del asociacionismo juvenil en los años 90. Instituto de la Juventud, Madrid.

RORTY, R. (1998): Derechos humanos, racionalidad y sentimentalidad. En SHUTE, A. y HURLEY, S. (Eds.): De los derechos humanos. Trotta, Madrid.

RUBIO CARRACEDO, J. (2000): Ciudadanía compleja y democracia. En RUBIO CARRACEDO, J.; ROSALES, J.M. y TOSCANO, M.

Ciudadanía, nacionalismo y derechos humanos. Trotta, Madrid, pp. 2145,

TAYLOR, C. (1994): La ética de la autenticidad. Paidós, Barcelona.

VALCÁRCEL, A. (1993): Del miedo a la igualdad. Crítica, Barcelona.

\section{NOTAS}

[1] El perfil según el nivel de estudios está condicionado por su naturaleza urbana de la muestra.

[2] Hoy habría que añadir el valor de la solidaridad, cuya ausencia 


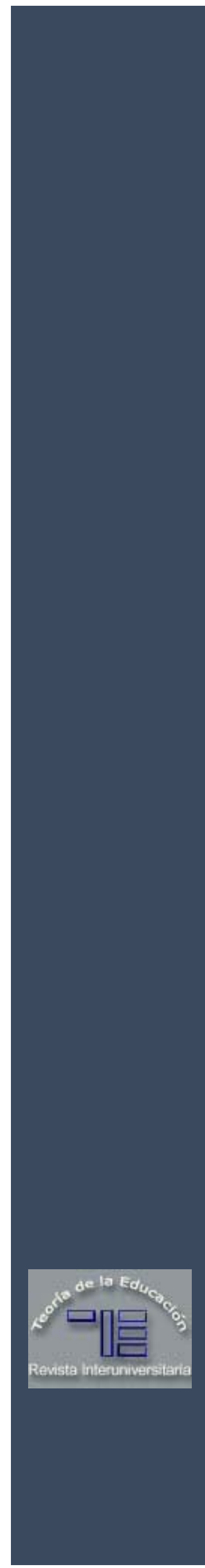

refuerza aún más la idea del carácter contextualizado en una realidad histórica muy determinada del artículo 1.1 de la Constitución.

[3] La estructura y tamaño de nuestra muestra no permite obtener resultados suficientemente fiables por zonas o comunidades autónomas. Sobre la identificación etnoterritorial y la propensión al "localismo" de la juventud española a lo largo de la última década, véase: Martín Serrano y Velarde Hermida (1997, pp. 233 ss.); Andrés Orizo (1999, pp. 107-118); Moral y Mateos (1999). Sobre las actitudes religiosas de los jóvenes, puede consultarse el reciente estudio de Elzo y González-Anleo (1999).

[4] Para la interpretación de este resultado debe tenerse en cuenta el carácter básicamente urbano de la muestra, pues, como han puesto de manifiesto otras investigaciones, el interés de los jóvenes por la política aumenta en las poblaciones más grandes, así como en función del nivel de estudios (Angulo Uribarri, 1995, p. 82; Morán y Benedicto, 1995, p. 65).

[5] Estos datos proceden del estudio Juventud y ocio, realizado por el autor en 1997 con una muestra de 2140 jóvenes.

[6] Según este estudio, que se basa en datos de 1999, en una escala de autoposicionamiento político del 1 al 10 , en la que el 1 representa las posiciones de izquierda y el 10 las de derecha, la media de la juventud (15-24 años) se inclina hacia la izquierda, situándose en torno al 4,6, si bien casi un $19 \%$ de jóvenes no aciertan a ubicarse políticamente. En intención de voto, la relación se invierte a favor del centro derecha, que recogería parte del voto de los que ideológicamente se sitúan ligeramente a la izquierda (Andrés Orizo, 1999, pp. 99-103).

[7] Según las siguientes puntuaciones, en una escala del 0 al 10: estudian $(7,1)$, trabajan $(7)$, están en paro o en busca del primer empleo $(6,8)$, realizan como actividad principal trabajos del hogar $(6,6)$. 